\title{
Materials Inventory Database for the Light Water Reactor Sustainability Program
}

Kazi Ahmed

Shannon M. Bragg-Sitton

August 2013

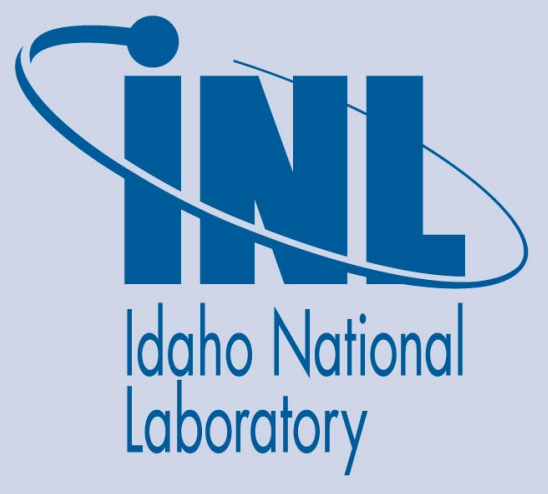

The INL is a U.S. Department of Energy National Laboratory operated by Battelle Energy Alliance 
INL/EXT-13-29960

\title{
Materials Inventory Database for the Light Water Reactor Sustainability Program
}

\author{
Kazi Ahmed \\ Shannon M. Bragg-Sitton
}

August 2013

\author{
Idaho National Laboratory \\ Light Water Reactor Sustainability Program \\ Idaho Falls, Idaho 83415
}

http://www.inl.gov

Prepared for the

U.S. Department of Energy

Office of Nuclear Energy

Under DOE Idaho Operations Office

Contract DE-AC07-05ID14517 


\section{DISCLAIMER}

This information was prepared as an account of work sponsored by an agency of the U.S. Government. Neither the U.S. Government nor any agency thereof, nor any of their employees, makes any warranty, expressed or implied, or assumes any legal liability or responsibility for the accuracy, completeness, or usefulness, of any information, apparatus, product, or process disclosed, or represents that its use would not infringe privately owned rights. References herein to any specific commercial product, process, or service by trade name, trade mark, manufacturer, or otherwise, does not necessarily constitute or imply its endorsement, recommendation, or favoring by the U.S. Government or any agency thereof. The views and opinions of authors expressed herein do not necessarily state or reflect those of the U.S. Government or any agency thereof. 



\section{Materials Inventory Database For the Light Water Reactor Sustainability Program}

INL/EXT-29960

August 2013

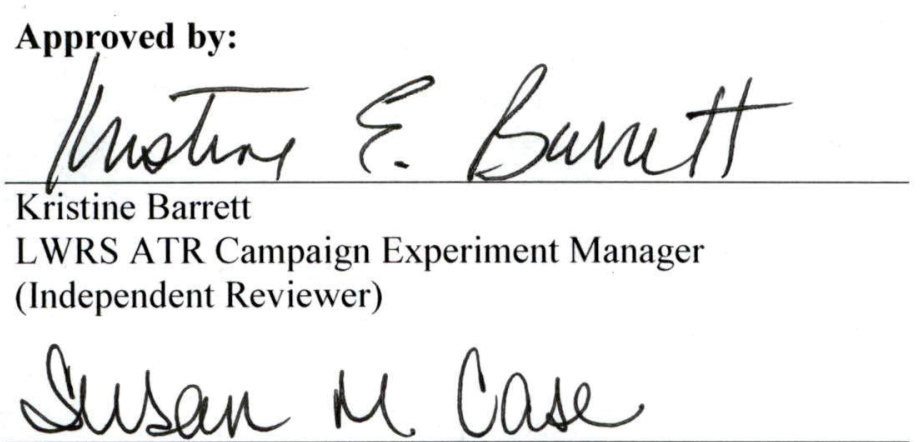

Susan Case

LWRS Logistics Coordinator

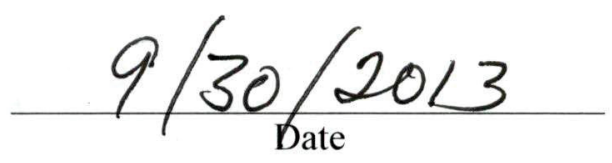

(Technical Reviewer) 


\begin{abstract}
Scientific research involves the purchasing, processing, characterization, and fabrication of many sample materials. The history of such materials can become complicated over their lifetime - materials might be cut into pieces or moved to various storage locations, for example. A database with built-in functions to track these kinds of processes facilitates well-organized research. The Material Inventory Database Accounting System (MIDAS) is an easy-to-use tracking and reference system for such items.

The Light Water Reactor Sustainability Program (LWRS), which seeks to advance the long-term reliability and productivity of existing nuclear reactors in the United States through multiple research pathways, proposed MIDAS as an efficient way to organize and track all items used in its research. The database software ensures traceability of all items used in research using built-in functions which can emulate actions on tracked items - fabrication, processing, splitting, and more - by performing operations on the data. MIDAS can recover and display the complete history of any item as a simple report.

To ensure the database functions suitably for the organization of research, it was developed alongside a specific experiment to test accident tolerant nuclear fuel cladding under the LWRS Advanced Light Water Reactor Nuclear Fuels Pathway. MIDAS kept track of materials used in this experiment from receipt at the laboratory through all processes, test conduct and, ultimately, post-test analysis. By the end of this process, the database proved to be right tool for this program. The database software will help LWRS more efficiently conduct research experiments, from simple characterization tests to inreactor experiments. Furthermore, MIDAS is a universal tool that any other research team could use to organize their material inventory.
\end{abstract}




\section{CONTENTS}

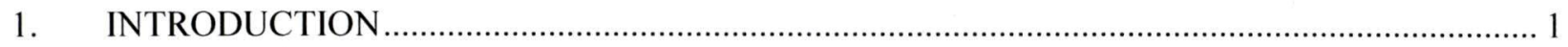

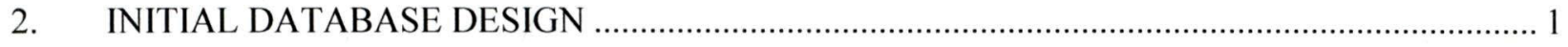

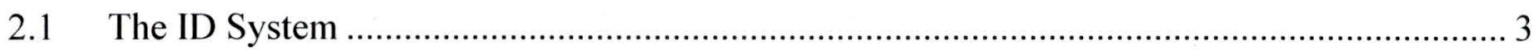

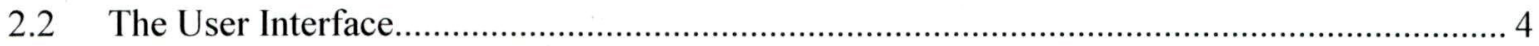

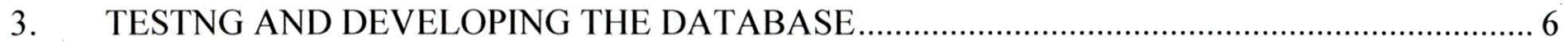

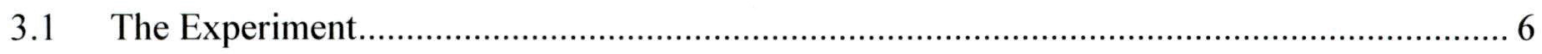

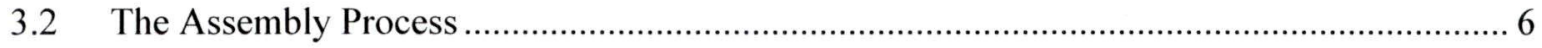

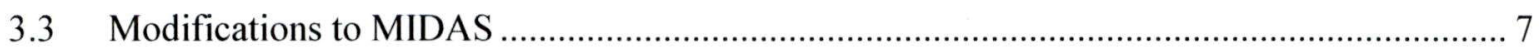

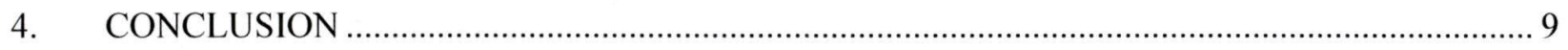

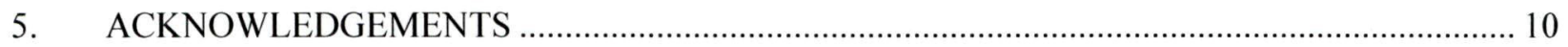

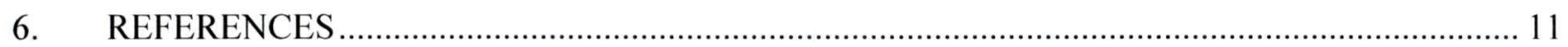




\section{INTRODUCTION}

Nuclear power accounts for about 20 percent of electrical power generation in the United States. As demand for electrical energy grows, advancing the long-term reliability and productivity of existing nuclear reactors is an economical way to meet energy needs. The Light Water Reactor Sustainability (LWRS) Program aims to extend nuclear power plant operating life in the U.S. with multiple research pathways in order to address this goal. ${ }^{1}$ This project is part of the Advanced Light Water Reactor Nuclear Fuels Pathway within the LWRS program, which seeks to improve knowledge about nuclear fuel and cladding performance. With this research, LWRS will develop improved fuel and cladding designs for existing nuclear reactors.

Nuclear fuel performance research - and scientific research in general - involves the purchasing, processing, characterization, and fabrication of many sample materials and fabricated components. LWRS proposed creating the Material Inventory Database Accounting System (MIDAS) as a tracking and reference system for such materials used in its research. During development, the database software must demonstrate its value by tracking items used in an experiment under LWRS. MIDAS should ensure traceability of all items used in research, and streamline organization of the program's research inventory.

\section{INITIAL DATABASE DESIGN}

MIDAS is a Microsoft Access database with supporting code written in Visual Basic for Applications (VBA). Individual parts are listed as rows, known as records, and information about each part is listed in columns, known as fields. Microsoft Access is a better organizational tool than Microsoft Excel for this kind of information for a few reasons. Access has built-in crosstable reference functionality, so it is easy to keep supporting information in separate tables, referencing them when necessary. Access also supports attachments, so documents such as 
material certification and analysis reports can be directly referenced in the database. Most importantly, VBA code allows for automation of repetitive database management tasks.

All items tracked by MIDAS start in the Raw Materials table. It contains important information about the material such as serial and lot numbers, the supplier, date received, as well as a description of the material. This is intended to be just an organizational tool for material procurement, listing items as they are purchased (Figure 1). Before any actions are performed on these materials, they must be imported into the Material Inventory table, which is the heart of the database. This table lists descriptive information about items, such as size, quality level, processing performed, etc. (Figure 2). These tables reference supporting information in other tables, such as personnel contact information, storage locations, statements of work, etc.

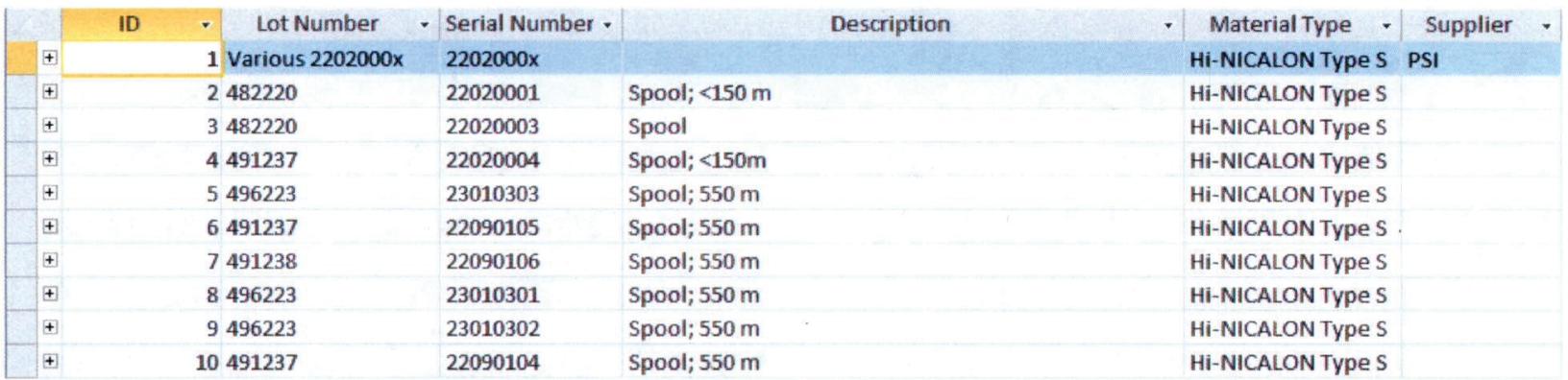

Figure 1: An excerpt from the raw materials table

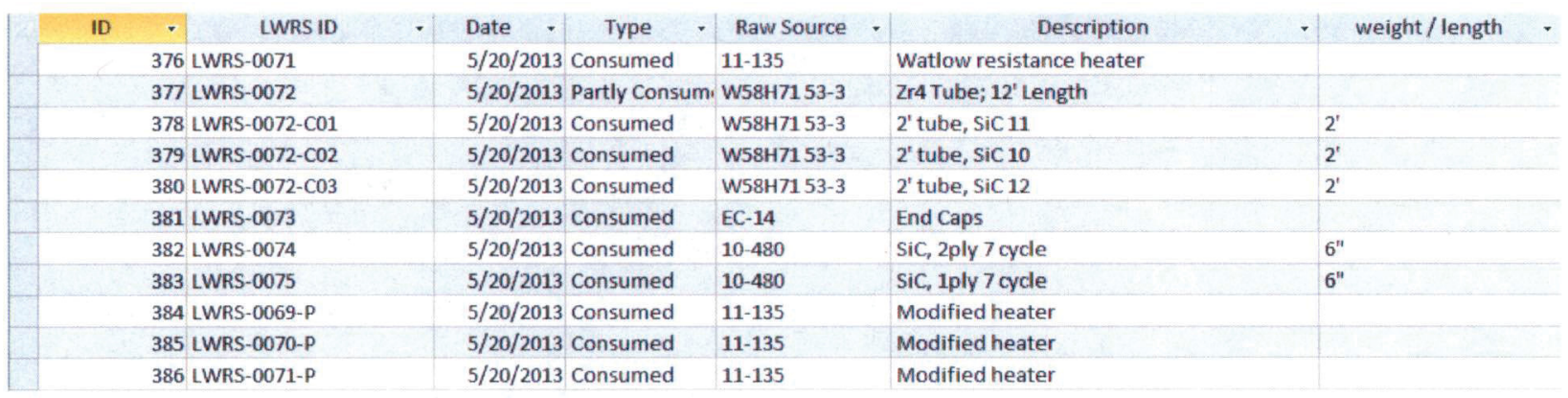

Figure 2: An excerpt from the material inventory table 


\subsection{The ID System}

As items undergo changes during research, these changes should be reflected in the database. Database management is time consuming, so MIDAS has a set of VBA functions to perform these changes with minimal user input. MIDAS generates a unique ID for each item imported to the Material Inventory table. When executed, the VBA functions emulate actions taken on a given tracked item - fabrication, processing, cutting, and more - by creating a new record with a modified ID based on the original item ID. Rather than modify the existing record, these functions create a new record in order to maintain the complete history of tracked items. This new ID is marked with a suffix to indicate what led to its generation (Table 1). This system allows the user to understand the history of an item just by looking at its ID; MIDAS also relies on these IDs to determine how it should alter records when its functions are called.

Table 1: Item ID suffixes

\begin{tabular}{lll}
\hline Action & Description & Suffix \\
\hline Cut & A material is divided into pieces & $-\mathrm{Cxx}$ \\
Process & A process is applied to a material, changing it physically & $-\mathrm{P}$ \\
Fabricate & Items are combined together to create a new assembly & $-\mathrm{F}$ \\
Recover & A fabricated item is disassembled, yielding its components & $-\mathrm{R}$ \\
\hline
\end{tabular}

Take an example item which is imported to the Material Inventory table with the ID "Item0015". This part is then cut into three pieces - invoking the cut control yields three new records, the third of which would be "Item-0015-C03". Information about cut dimensions is stored in a separate field. If this item is then processed, another record is created called "Item-0015-C03-P". The specific type of process is not specified in the ID, but in a separate field. While records and their IDs can be changed manually, it is better to let the VBA code handle the ID system to ensure consistency and code functionality. 


\subsection{The User Interface}

Each table in Microsoft Access has a corresponding window where the user can view or change information for one record at a time. Most of the time spent using MIDAS will be in the Material Inventory window, which displays part information and allows the user to call any of the built-in functions available (Figure 3). Cutting and processing materials is simple, as shown in Figure 4 on the next page. The program asks for some information in a new window, then creates new records and populates them automatically. Fabricating and disassembling materials is more complicated and will be explained in more detail.

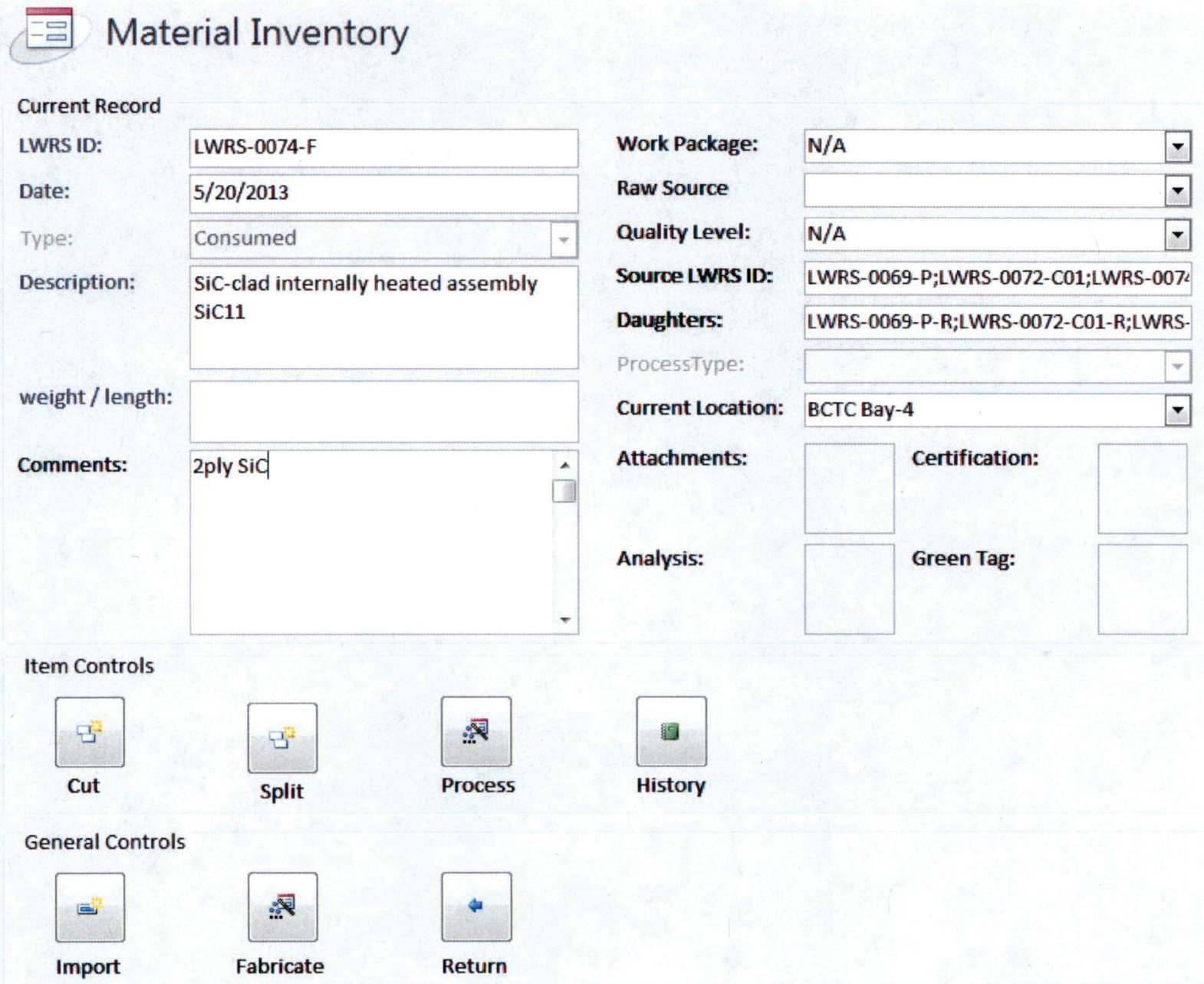

Figure 3: The Material Inventory window 

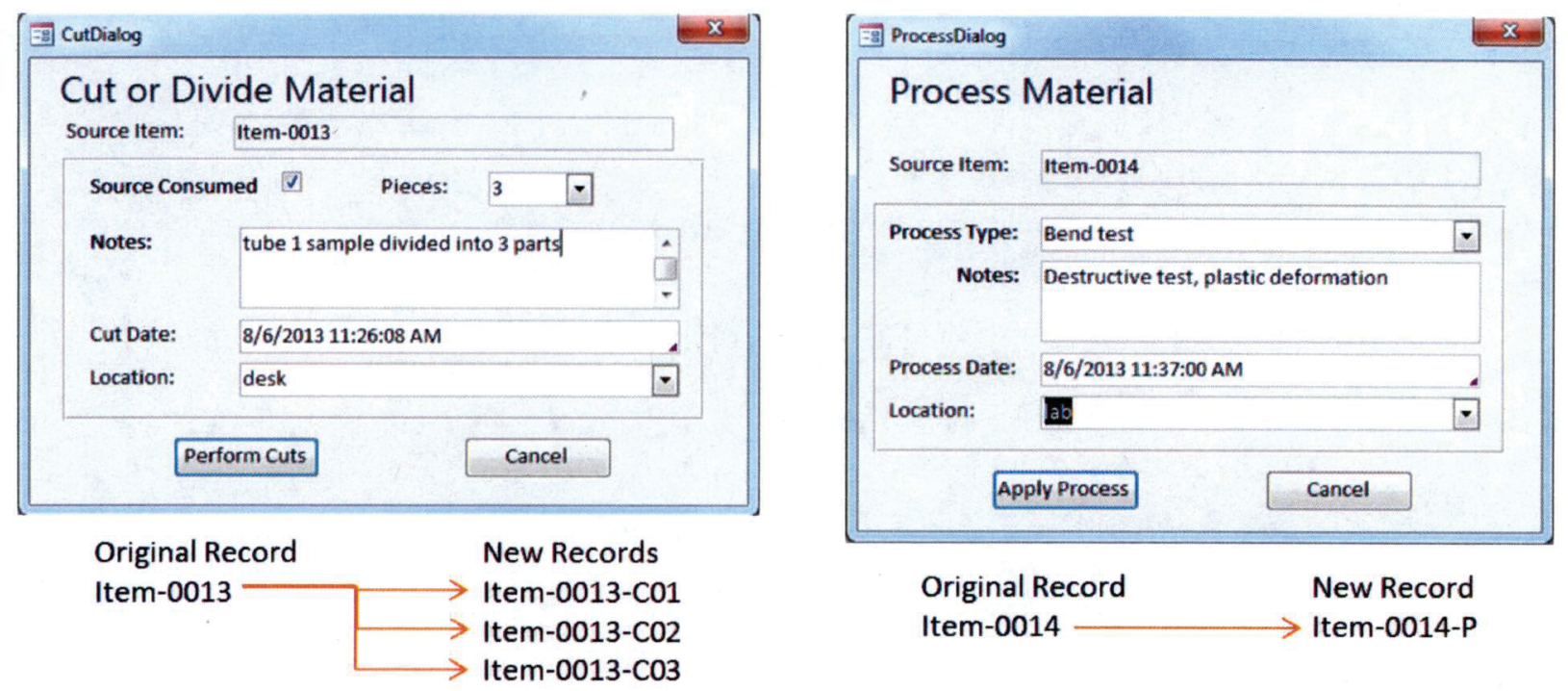

Figure 4: Cutting and processing material

The Fabricate command is used when multiple items are used to assemble a new material. Any number of items can be selected for this process (Figure 5). In this example, a new record will be created with the name "LWRS-0078-F". This single ID cannot reflect every single part used in the fabrication of the item, so the list of these parts is stored in a separate field.

\begin{tabular}{|c|c|c|}
\hline \multicolumn{2}{|c|}{ 명 FabricateDialog } & $-x$ \\
\hline \multicolumn{3}{|c|}{ Fabricated Materials } \\
\hline IWRS ID: & LWRS-0078-F & \\
\hline \multirow[t]{2}{*}{ Source LWRS ID: } & LWRS ID & Description \\
\hline & LWRS-0072 & Zr4 Tube; 12 ' Length \\
\hline \multirow[t]{11}{*}{ (Expand ID Field) } & LWRS-0072-C01 & 2 tube, sic 11 \\
\hline & LWRS-0072-C01-R & 2' tube, SiC 11 \\
\hline & LWRS-0072-C02 & 2' tube, SiC 10 \\
\hline & LWRS-0072-C02-R & $2^{\prime}$ tube, $\mathrm{SiC} 10$ \\
\hline & LWRS-0072-C03 & 2 tube, Sic 12 \\
\hline & LWRS-0072-C03-R & 2' tube, SiC 12 \\
\hline & LWRS-0072-C03-R-F & Bare internally heated asse \\
\hline & LWRS-0073 & End Caps \\
\hline & LWRS-0073-F & Bare internally heated asse \\
\hline & LWRS-0074 & Sic, 2 ply 7 cycle \\
\hline & LWRS-0074-F & Sic-clad internally heated a - \\
\hline Include Raw Source? & e?: $O$ Yes & \\
\hline Raw Serial \#: & none & - \\
\hline Description: & Tube assembly & \\
\hline \multicolumn{2}{|c|}{ Figure 5: The Fabricate window } & 4 \\
\hline Current Location: & BCTC Bay-4 & - \\
\hline \multicolumn{2}{|c|}{ Fabricate Materials } & Cancel \\
\hline
\end{tabular}

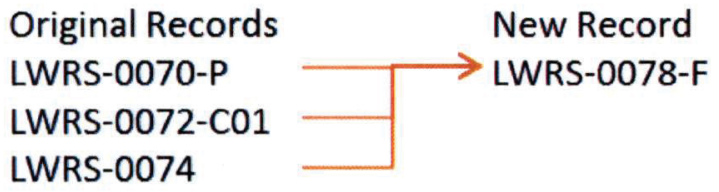

The database software was initially developed according to this overall design, but without the ability to disassemble 
fabricated items, and lacking information and functionality to make viewing and understanding the history of a part a simple process. Testing the ability of the database to track materials used in an actual experiment revealed what features the database lacked and what changes needed to be made. This methodology helps ensure the database is suitable for tracking scientific research.

\section{TESTNG AND DEVELOPING THE DATABASE \\ 3.1 The Experiment}

MIDAS was tested by tracking materials through the fabrication process for a specific experiment. The LWRS Advanced Light Water Reactor Nuclear Fuels Pathway is investigating the use of Silicon-Carbide Ceramic Matrix Composites (SiC-CMC) as a more accident-tolerant nuclear fuel cladding material. The potential advantages of $\mathrm{SiC}$ cladding include increased corrosion resistance and reduced hydrogen generation during accident conditions when the cladding is exposed to steam. ${ }^{2}$ Potential cladding material such as SiC-CMC must go through relatively low-cost, nonnuclear mechanical, thermal, and chemical characterization tests; only the best technologies selected by these tests will be used for in-reactor tests. ${ }^{3}$ This experiment investigates how Zircaloy-4 cladding tubes surrounded by a SiC-CMC sleeve behave under thermal stress. To simulate the heat generated by nuclear fission, electrical resistance heaters must be installed inside these cladding tubes. The assemblies will be tested in a hot water corrosion flow test loop - to simulate reactor water flow conditions - located at one of the INL facilities. The database would need to keep track of these throughout the sample preparation process: from the point of receipt at the laboratory through cutting, fabrication, test conduct and, ultimately, post-test analysis.

\subsection{The Assembly Process}

Test design specifications determined how as-received parts would need to be modified for the assembly of internally heated cladding rods (Figure 6). First, the $\mathrm{Zr}-4$ is cut to an appropriate 
size and the appropriate $\mathrm{SiC}-\mathrm{CMC}$ sleeve is attached to the outside. The stock resistance heaters come with a metal sheath which must be removed. The ceramic coating over the resistor coils in the heater is then removed, and the heater is recast with a new ceramic layer of appropriate diameter. This heater is then coated with a lubricant and placed inside the cladding tube. This entire heater modification process is considered one process in the database.

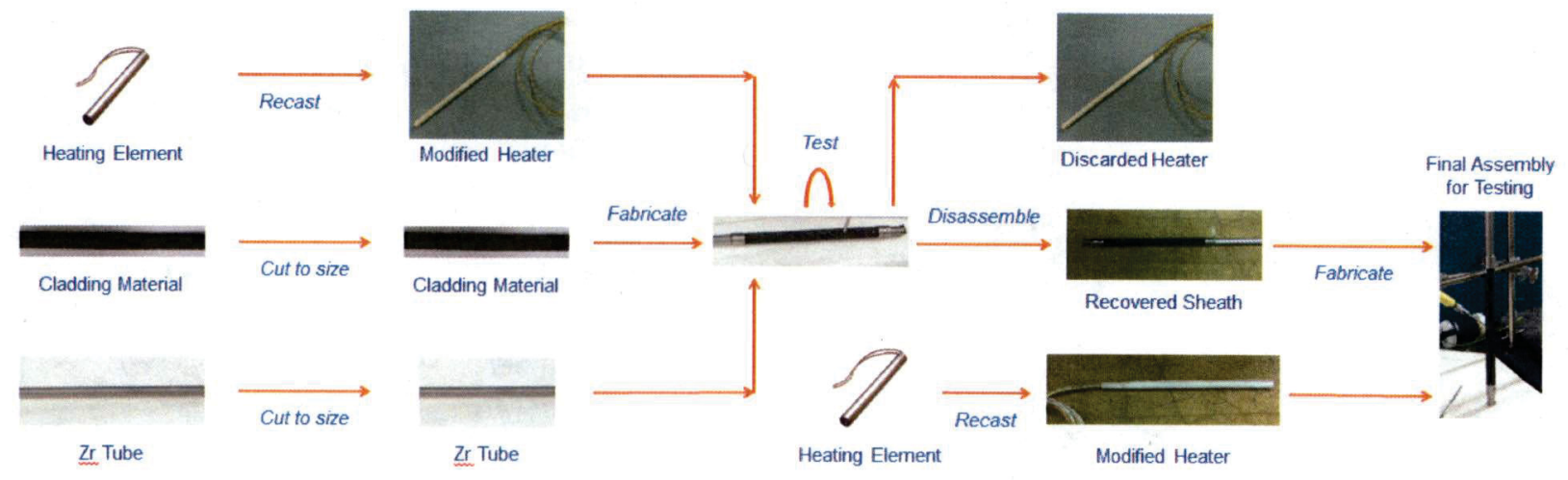

Figure 6: The internally-heated fuel cladding assembly process

Initial testing of these assemblies revealed an electrical issue. The internal thermocouples of the heaters were contacting the metal sheaths, which created significant error in temperature measurements. Even when isolated, the Zr-4 sheaths acted like antennae, altering the thermocouple voltage reading. The cladding assemblies had to be disassembled to address this issue. The $\mathrm{Zr}-4$ and SiC-CMC cladding was saved, and the old heaters set aside. New heaters were recast with the same process, but with the thermocouple slightly adjusted. The total assemblies were fabricated again, using the same cladding tubes, but with the newly recast heaters.

\subsection{Modifications to MIDAS}

The sample preparation process for this experiment revealed the need for new features in MIDAS. Fabricated parts like the first internally heated cladding assembly might need to be taken apart, and their components recovered. In cases like this, using the cut control does not 
make intuitive sense, as one single material is not being divided. The database required a function that could emulate the disassembly of a fabricated material, so the split function was developed. This takes the list of all materials that were combined into a fabricated part, and creates new records for these pieces, which are considered "recovered" (Figure 7). This function tracked the disassembly of the first internally heated cladding rods. Their recovered parts, with the heater replaced, could then be fabricated into new internally heated cladding tubes.
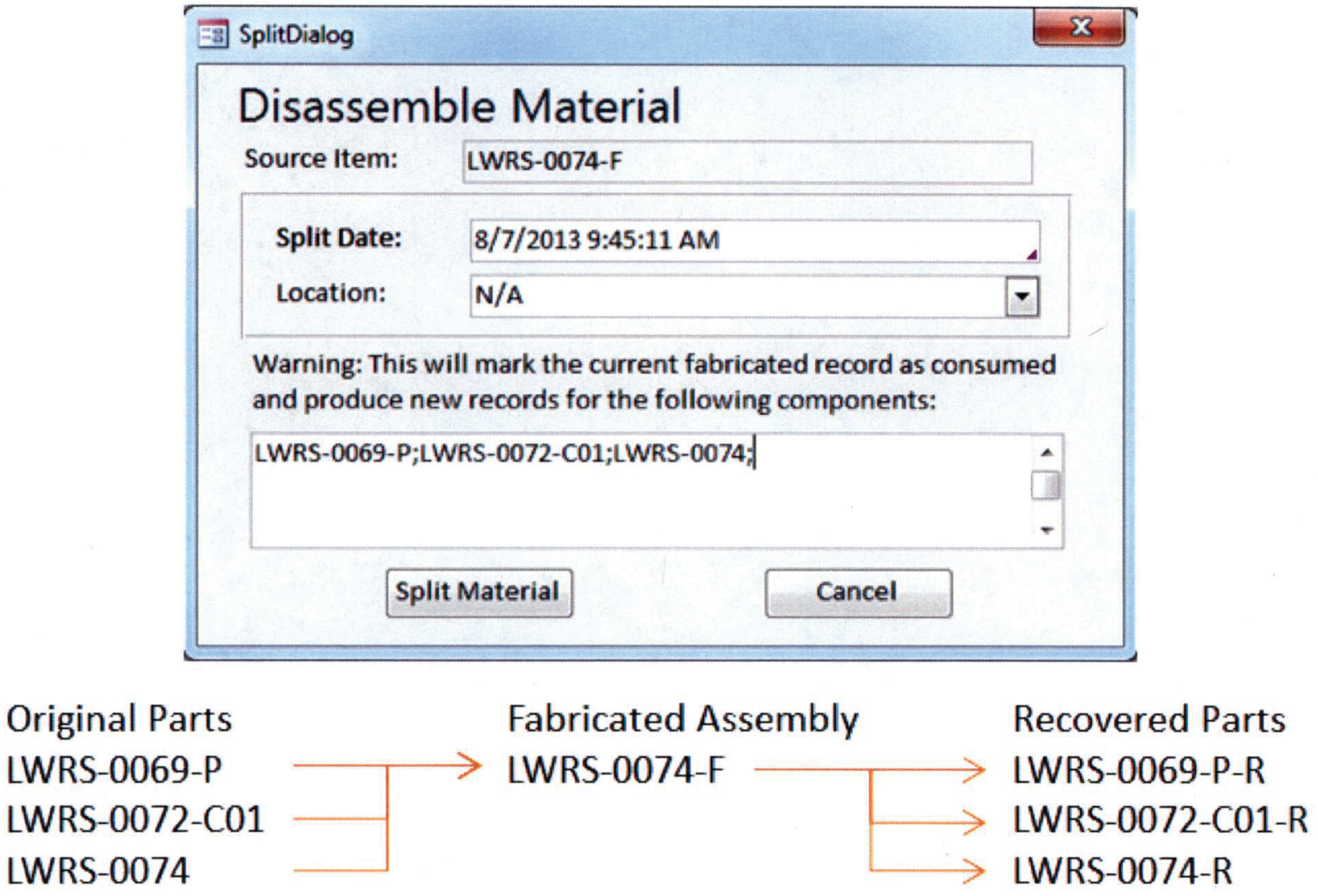

Figure 7: Disassembling a fabricated part

Although the ID system provides a way to manually trace the history of a part, this can still be time consuming. The sample assembly process for the internally heated cladding tube experiment revealed the potential complexity of item histories. Tracing items back through processing or cutting is simple, but fabrication and disassembly are much more difficult to 
follow. The part history function addresses this issue - it recovers an item's complete history and displays it as an Access report (Figure 8).

This function starts with the ID of the item to be investigated. If the part is cut or processed, it simply finds the record for the item's previous state by removing the suffix. If an item has been fabricated, it checks the source item field for the list of all its components, and follows their individual histories by calling itself for each of those components. The function will also include the fabricated item that a recovered part came from. In Figure 8, the source field lists the components of a fabricated assembly, and the fabricated item that yielded a given recovered item upon disassembly. Furthermore, the daughter field contains the list of parts that result from applying a function to a given part.

\begin{tabular}{|c|c|c|c|c|c|c|}
\hline \multicolumn{7}{|c|}{ Part History } \\
\hline LWRS ID) & Date & Type & Description & Comments & Source LWRS ID & Daughter Material \\
\hline LWRS-0072 & $5 / 20 / 2013$ & Partly Consum & Zr4 Tube; 12' Length & & & $\begin{array}{l}\text { IWRS-0072-C01;LWRS- } \\
\text { 0072-C02;LWRS-0072- } \\
\text { C03; }\end{array}$ \\
\hline LWRS-0072-C01 & $5 / 20 / 2013$ & Consumed & 2' tube, SiC 11 & & & IWRS-0074-F; \\
\hline L.WRS-0074 & $5 / 20 / 2013$ & Consumed & SiC, 2 ply 7 cycle & & & IWRS-0074-F; \\
\hline LWRS-0074-F & $5 / 20 / 2013$ & Fabricated & $\begin{array}{l}\text { SiC-clad internally heated } \\
\text { assembly SiC11 }\end{array}$ & 2 ply SiC & $\begin{array}{l}\text { LWRS-0069-P;IWRS- } \\
\text { 0072-C01;LWRS-0074; }\end{array}$ & $\begin{array}{l}\text { LWRS-0069-P-R;LWRS- } \\
0072 \text {-C01-R;LWRS-0074 } \\
\text { R; }\end{array}$ \\
\hline LWRS-0076 & $6 / 24 / 2013$ & Consumed & Watlow resistance heater & & & IWRS-0076-P; \\
\hline LWRS-0076-P & $7 / 1 / 2013$ & Consumed & Modified heater & & & IWRS-0076-P-F; \\
\hline LWRS-0072-C01-R & $7 / 15 / 2013$ & Consumed & 2' tube, SiC 11 & & LWRS-0074-F & LWRS-0076-P-F; \\
\hline LWRS-0074-R & $7 / 15 / 2013$ & Consumed & SiC, 2 ply 7 cycle & & IWRS-0074-F & IWRS-0076-P-F; \\
\hline LWRS-0076-P-F & $7 / 17 / 2013$ & Fabricated & $\begin{array}{l}\text { SiC-clad internally heated } \\
\text { assembly SiC11 }\end{array}$ & 2 ply SiC & $\begin{array}{l}\text { LWRS-0072-C01-R; LWRS- } \\
\text { 0074-R; LWRS-0076-P; }\end{array}$ & \\
\hline
\end{tabular}

Figure 8: The history of a fabricated part

\section{CONCLUSION}

By the end of the cladding tube assembly process, MIDAS proved to be a suitable tool for tracking materials used in scientific research. This experiment revealed essential features that needed to be added to the database software. The ability to cut, process, fabricate, or disassemble items should allow users to represent any changes made to materials. Most importantly, MIDAS 
has the ability to identify any part's parents and children, as well as the complete history of the part. This ensures traceability of items used in research, makes it easy to verify the testing history of parts, and more. In the future, some additional functions could be made to further simplify database management. The need for such functions might become apparent as new experiments are conducted.

As the amount of data being tracked grows, the database might be converted to an SQL server. Compared to a simple Access file, server design has increased security and transaction logging - this is good for a project-wide file which multiple people may need to view and modify. For now, the streamlined material inventory organization will help LWRS more efficiently conduct research experiments, from simple characterization tests to in-reactor experiments. Since material states and the actions that can be applied to materials are universal in nature, MIDAS is suitable for tracking any kind of research - a generic version of the database is available for any research team to use.

\section{ACKNOWLEDGEMENTS}

- Sample fabrication planning and supervision

- Isabella J. Van Rooyen

- James E. O'Brien

- Timothy G. Kaser

- Amber R. Miller

- Kevin McHugh

- Matt Weseman

- Database testing and design suggestions

- Shannon M. Bragg-Sitton

- Kristine E. Barrett

- Susan M. Case

- Creation of first incarnation of database

- Steven R. Bryan 


\section{REFERENCES}

1. Light Water Reactor Sustainability Program Integrated Program Plan. Light Water Reactor Sustainability Program, U.S. Department of Energy. Office of Nuclear Energy, 2013. External Report. INL/EXT-11-23452. p.1

2. Barrett, K., Bragg-Sitton, S., and Galicki, D. Advanced LWR Nuclear Fuel Cladding System Development Trade-off Study. Light Water Reactor Sustainability Program, U.S. Department of Energy. Idaho Falls, ID: Idaho National Laboratory, 2012. External Report. INL/EXT-12-27090. p.21-28

3. Bragg-Sitton, Shannon. Advanced LWR Nuclear Fuel Cladding System Development Technical Program Plan. Light Water Reactor Sustainability Program, U.S. Department of Energy. Idaho Falls, ID: Idaho National Laboratory, 2012. External Report. INL/MIS12-25696. p.31 